\title{
Urinary Uric Acid/Creatinine Ratio as a Marker of Mortality and Unfavorable Outcome in NICU-Admitted Neonates
}

\author{
Shahin Nariman, ${ }^{1}$ Ziba Mosayebi, ${ }^{1,2}$ Setareh Sagheb, ${ }^{1,{ }^{*}}$ Hadith Rastad, ${ }^{3}$ and Seyyed Saeed \\ Hosseininodeh $^{2}$ \\ ${ }^{1}$ Department of Pediatrics, Tehran University of Medical Sciences, Tehran, IR Iran \\ ${ }^{2}$ Children's Medical Center, Pediatric Center of Excellence, Tehran, IR Iran \\ ${ }^{3}$ Research Development Center, Arash Hospital, Tehran University of Medical Sciences, Tehran, IR Iran \\ *Corresponding author: Setareh Sagheb, Department of Pediatrics, Tehran University of Medical Sciences, Tehran, IR Iran. Tel: +98-9122387976, E-mail: dr.ssagheb@yahoo.com
}

Received 2016 February 19; Revised 2016 April 17; Accepted 2016 May 13.

\begin{abstract}
Background: The survival of neonates who have been admitted to the NICU, especially premature infants with few mortality and morbidity, is the most important attitude.

Objectives: We presumed whether urinary uric acid/creatinine (UUA/Cr) ratio can be a marker of mortality and adverse outcome in neonates which were admitted to the NICU.

Patients and Methods: All preterm infants admitted to our NICU after birth from March 2014 to April 2015 were enrolled in this prospective cohort study. UUA/Cr was measured during the first day of life. The severity of diseases (indicated by the need for high setup of mechanical ventilation, complications of prematurity, and duration of stay in the NICU) and neonatal death were considered to be the final unfavorable outcomes. The relationship between the Log-transformation (Ln) urinary uric acid/creatinine ratio and the Apgar score at the first and $5^{\text {th }}$ minute after birth and the duration of stay were analyzed by using linear regression. Statistical analysis was done by using STATA version 11 (STATA Corp, TX, USA). A P $<0.05$ was considered to be statistically significant.

Results: A total of 362 preterm infants with a mean gestational age of 32.7 ( \pm 3.9 ) weeks were admitted to the NICU, out of whom 64 (17.6\%) had severe disease and 43 (11.8\%) died. The mean UUA/Cr ratio was significantly higher in the admitted neonates (3.30 \pm 1.95 vs. $1.36 \pm 0.42 . P=0.0001)$. There was a negative correlation between the UUA/Cr ratio and the 1-minute Apgar score $(r=-0.17, P$ $=0.006)$ and the 5 -minute Apgar score $(\mathrm{r}=-0.19, \mathrm{P}=0.003)$. The 1-minute Apgar scores were negatively correlated with the outcome $(\mathrm{OR}=0.68 ; \mathrm{P}<0.001)$ and the duration of stay $(\beta=-.28 ; \mathrm{P}<0.001)$. There was no significant correlation between 5-minute Apgar scores and the outcome. There was a significant positive correlation between the UUA/Cr ratio and an unfavorable outcome $(\mathrm{OR}=$ $1.24 ; \mathrm{CI} \% 95: 1.06$ to $1.43, \mathrm{P}=0.006)$ and increasing duration of $\operatorname{stay}(\beta=0.17 ; \mathrm{P}=0.009)$.

Conclusions: The urinary uric acid/creatinine ratio can be used as a simple, noninvasive parameter of the severity of disease and mortality in NICU-admitted neonates.
\end{abstract}

Keywords: Urinary Uric Acid to Creatinine Ratio, Mortality, Newborn, Outcome

\section{Background}

The survival of neonates who have been admitted to NICU, especially premature infants with few mortality and morbidity, is the most important attitude.

Due to some limitations, the Apgar score cannot be used as a useful tool for the evaluation of newborns. Different factors, especially prematurity, can have an effect on it, as a result of which it cannot anticipate mortality and morbidity definitively (1). There are many studies which have focused on evaluation of risk factors for prediction of mortality and severity of disease, especially in perinatal asphyxia (1-5), bronchopulmonary dysplasia (6), cardiovascular disorders (7), and respiratory distress syndrome (RDS) (8). There are different scoring systems for assessing neonatal mortality $(9,10)$. These scoring systems contain many items, and sometimes checking takes hours; as a result, they can be very time-consuming in some situations.

Increasing the activity of xanthine oxidase (XO) during the inflammatory process and neonatal sepsis has already been studied. Hypoxic ischemic events and inflammatory processes can cause renal damage, which leads to urinary uric acid excretion, which is a product of purine catabolism and free radicals due to the activation of xanthine oxidase (11-13). Previous studies have evaluated the UUA/Cr ratio as a predictor of mortality and severity of disease in perinatal asphyxia, and have established the correlation between the Apgar score and the urinary uric acid to creatinine ratio (4). Moreover, rising of serum uric acid as a predictor of mortality in critically ill children has already been reported (14) 


\section{Objectives}

The aim of this study was to evaluate the UUA/Cr ratio and to determine whether it can serve as a simple, accessible marker of the mortality and severity of disease in NICUadmitted neonates. According to our knowledge, this is the first time the UUA/Cr ratio has been used for studying the severity of various diseases during neonatal periods, except for perinatal asphyxia.

\section{Patients and Methods}

A prospective cohort study was conducted during 13 months from March 2014 to April 2015 on 362 preterm infants who were admitted to the NICU of Arash Hospital in Tehran, soon after birth. The study was approved by the local ethical committee.

All preterm infants with gestational ages of 26 to 36 6/7 weeks were included in the study. Inclusion criterion: preterm infants with respiratory disorders. Exclusion criteria: 1 , infants born to mothers with preeclampsia or chorioamnionitis; 2, major congenital abnormalities at birth. To avoid any confounding effects, the first urine samples were collected with a urine bag within 24 hours after birth and the urinary ratio of uric acid to creatinine (UUA/Cr) was performed using the uricase-peroxidase enzymatic method. The need for high set-up of mechanical ventilation, complications of prematurity (respiratory distress syndrome (RDS), late onset sepsis, patent ductus arteriosus (PDA), necrotizing enterocolitis (NEC), pulmonary air leak syndrome, bronchopulmonary dysplasia (BPD), and duration of stay in the NICU were defined as the severity of disease. Mortality and the severity of disease were considered to be the final unfavorable outcomes.

As an initial step, descriptive statistics for all variables were produced. The results were presented as arithmetic mean \pm standard deviation for continuous variables with normal distribution. The duration of stay and the UUA/Cr ratio showed a skewed distribution in all groups, so log-transformation (Ln) was applied and the geometric mean calculated. Proportions were presented for categorical data. The relationship between the Ln urinary uric acid/creatinine ratio and the Apgar score at the $1_{\text {st }}$ and $5^{\text {th }}$ minute of birth and duration of stay, on the other, was analyzed by using linear regression.

Univariable logistic regression was used in order to measure the strength and direction of the association between the urinary uric acid/creatinine ratio and the Apgar score at the $1_{\text {st }}$ and $5^{\text {th }}$ minute of birth and outcome.

A P $<0.05$ was considered to be significant. Statistical analyses were performed by using STATA version 11 (STATA Corp., TX, USA).

\section{Results}

Out of the 362 premature neonates who were admitted to our NICU from March 2014 to April 2015, 298 were discharged without any complication and were included in the control group, while $64(17.6 \%)$ had a severe disease, out of whom $43(11.8 \%)$ died. These constituted the case group. Demographic profiles of patients in each subgroup are shown in Table 1. RDS was the most frequent cause of admission.

There are negative correlations between the UUA/Cr ratio and the $1_{\text {st }}$ minute Apgar score ( $\left.\mathrm{r}:-0.17, \mathrm{P}=0.006\right)$ and the $5^{\text {th }}$ minute Apgar score ( $\left.\mathrm{r}:-0.19, \mathrm{P}=0.003\right)$. The arithmetic means of the UUA/Cr ratio and the $1^{\text {st }}$ minute Apgar score were 3.14 and 7 respectively in discharged infants without any compilation compared to 3.96 and 4 in the dead group, and 4.31 and 6 in the other group. The mean differences in both of them were statistically significant. We also compared the mean UUA/Cr ratio of NICUadmitted infants $(3.30 \pm 1.95)$ with the mean of this ratio for healthy infants who were born in our hospital (1.36 $\pm 0.42)$, and a statistically significant difference was also found $(\mathrm{P}=0.001)$.

The duration of stay and the UUA/Cr ratio showed a skewed distribution in all groups, so log-transformation (Ln) was applied and the geometric means calculated. The correlation of the UUA/Cr ratio and the $1_{\text {st }}$ minute Apgar score with outcome and duration of stay is presented in Table 2 . The $1_{\text {st }}$ minute Apgar scores were negatively correlated with the outcome $(\mathrm{OR}=0.68 ; \mathrm{CI} \% 95: 0.60$ to $0.77, \mathrm{P}$ $<0.001)$ and the duration of stay $(\beta=-0.28 ; \mathrm{P}<0.001)$. In other words, each unit increase in the Apgar score ranging 5 and above at birth decreases the odds of a severe condition by $30 \%$. However, the UUA/Cr ratio was positively correlated with unfavorable outcome $(\mathrm{OR}=1.24 ; \mathrm{CI} \% 95: 1.06$ to $1.43, \mathrm{P}=0.006)$ and increased duration of $\operatorname{stay}(\beta=0.17 ; \mathrm{P}=$ $0.009)$.

\section{Discussion}

The prediction of mortality and morbidity for infants admitted to the NICU is the most important goal. The present study evaluates the UUA/Cr ratio as a single, simple test for this purpose and shows that it was elevated in all preterm neonates who were admitted, in comparison with healthy infants who were born in our hospital. Chen et al. reported that the urinary UA/Cr ratio was remarkably higher in hypoxic premature infants than in hypoxic term infants (15).

Bahubali et al. reported that this ratio was elevated in neonates with birth asphyxia compared with the control group, and that this ratio was correlated significantly 
Table 1. Demographic Profiles and Urine Uric Acid/Creatinine Ratio of Patients ${ }^{\mathrm{a}}$

\begin{tabular}{|c|c|c|c|c|}
\hline Variables & Survived $(\mathbf{n}=\mathbf{2 5 5})$ & Severe $(n=64)$ & Dead $(n=43)$ & Total $(n=362)$ \\
\hline Birth weight, kg & $2.11 \pm 0.75$ & $1.81 \pm 0.91$ & $1.35 \pm 0.78$ & $1.97 \pm 0.81$ \\
\hline Apgar score (1 $1_{\text {st }}$ minute) & $7 \pm 2$ & $6 \pm 1$ & $4 \pm 2$ & $7 \pm 2$ \\
\hline Urinary uric acid/creatinine ratio $\mathrm{mg}$ uric acid/creatinine, $\mathrm{mg}$ & $3.14 \pm 1.67$ & $4.31 \pm 1.60$ & $3.96 \pm 3.24$ & $3.30 \pm 1.95$ \\
\hline Mean gestational age, week & $33.3 \pm 3.5$ & $31.8 \pm 3.07$ & $29.91 \pm 4.6$ & $32.7 \pm 3.9$ \\
\hline \multicolumn{5}{|l|}{ Gender, \% } \\
\hline Male & 46.0 & 38.1 & 46.4 & 45.6 \\
\hline Female & 54.0 & 61.9 & 53.6 & 54.4 \\
\hline \multicolumn{5}{|l|}{ Cause of Admission, \% } \\
\hline RDS & 67.0 & 76.2 & 85.7 & 70.4 \\
\hline TTN & 22.5 & 4.8 & 1.8 & 18.2 \\
\hline Prematurity & 6.7 & 4.8 & 1.8 & 5.8 \\
\hline Pneumonia & 0.7 & 0.0 & 1.8 & 0.8 \\
\hline Others & 3.1 & 14.2 & 9.7 & 4.8 \\
\hline
\end{tabular}

${ }^{\mathrm{a}}$ Values are expressed as mean $\pm \mathrm{SD}$ unless otherwise indicated.

Table 2. Correlation of Urinary Uric Acid/Creatine Ratio and $1_{\text {st }}$ Minute Apgar Score With Duration of Stay and Outcome

\begin{tabular}{|c|c|c|c|c|}
\hline Predictors & $\begin{array}{c}\text { Unfavorable Outcome }{ }^{\mathrm{a}} \text { Odds Ratio (Confidence } \\
\text { Interval 95\%) }\end{array}$ & P Value & $\mathrm{Ln}^{\mathrm{b}}$ Duration of Stay Beta $\left(\mathrm{SE}^{\mathrm{c}}\right)$ & P Value \\
\hline In urinary uric acid/creatinine ratio (UUA/Cr) & 1.24 (1.06 to 1.43$)$ & 0.006 & $0.17 \pm 0.06$ & 0.009 \\
\hline 1st $_{\text {st }}$ minute Apgar Score & $0.68(0.60$ to 0.77$)$ & $<0.001$ & $-0.28 \pm 0.02$ & $<0.001$ \\
\hline
\end{tabular}

with the clinical severity of the disease. They also reported a significant negative correlation between this ratio and the Apgar score (16), which was also indicated in studies by Banupriya (2) and Bhongir (3). In our study, there was a weekly negative correlation between this ratio and the 1st and 5th Apgar scores.

Although in other studies this ratio was evaluated as a predictor of outcome only in prenatal asphyxia $(2,3)$, our study shows that the urinary uric acid excretion rate depends on the severity of renal damage during any condition which leads to severe unfavorable events and death, especially in preterm neonates. The UUA/Cr ratio increases with the severity of disease and is associated with longer duration of stay and adverse outcome in all NICU-admitted neonates.

The $1_{\mathrm{st}}$ minute Apgar scores were negatively correlated with the outcome and duration of stay, but there was no significant correlation between $5^{\text {th }}$ minute Apgar scores and outcome. This may be due to improper assessment of the Apgar score during resuscitation, so that the $5^{\text {th }}$ minute Apgar score was higher than expected. This is why the American academy of pediatrics recommends an expanded Apgar score for assessment of infants after birth (1).

According to the results of our study, the UUA/Cr ratio has the potential to act as a simple cost-effective, noninvasive, single biochemical marker for assessing the severity of disease and mortality, not only in prenatal asphyxia, but also in all unstable newborns admitted to the NICU. The UUA/Cr ratio in combination with the Apgar score and other scoring tools can contribute to early decisionmaking on the level of care that infants require.

\subsection{Limitation}

In this study, all complications of prematurity (RDS, IVH, NEC,...) were regarded as indicators of the severity of disease. There is a need to evaluate this marker for each disease separately and define the best cut-off value for each gestational age. 


\section{Acknowledgments}

We would like to thank Mr. Sayyed Ourmazd Mohseni for editing the article. We would also like to thank the nursing staff of Arash hospital for their help.

\section{Footnotes}

Authors' Contribution: Study concept and design, Ziba Mosayebi, Shahin Nariman, Setareh Sagheb; acquisition of data, Seyyed Saeed Hosseininodeh, Hadith Rastad; drafting of the manuscript, Setareh Sagheb, Seyyed Saeed Hosseininodeh; study supervision, Ziba Mosayebi, Shahin Nariman, Setareh Sagheb.

\section{Funding/Support: There is no financial support.}

\section{References}

1. Committee on Obstetric Practice American Academy of Pediatrics Committee on F. Committee Opinion No. 644: The Apgar Score. Obstet Gynecol. 2015;126(4):e52-5. doi: 10.1097/AOG.0000000000001108. [PubMed: 26393460]

2. Banupriya C, Doureradjou P, Mondal N, Vishnu B, Koner BC. Can urinary excretion rate of malondialdehyde, uric acid and protein predict the severity and impending death in perinatal asphyxia?. Clin Biochem. 2008;41(12):968-73. doi: 10.1016/j.clinbiochem.2008.04.011. [PubMed: 18471999].

3. Bhongir AV, Yakama AV, Saha S, Radia SB, Pabbati J. The Urinary Uric Acid/Creatinine Ratio is An Adjuvant Marker for Perinatal Asphyxia. EurJ Pharm Med Res. 2015;2(5):520-8. [PubMed: 26998526].

4. Basu P, Som S, Choudhuri N, Das H. Correlation between Apgar score and urinary uric acid to creatinine ratio in perinatal asphyxia. Indian J Clin Biochem. 2008;23(4):361-4. doi: 10.1007/s12291-008-0079-2. [PubMed: 23105787].
5. Hesham I, Alaa- Eldin S. Study of serum markers of brain in jury as early predictors of neonatal hypoxia/ischemia. Alex J Pedatr. 2005;19:77-82.

6. Hussein NF, Helaly N, Ghanya E, Anisb S. Relationship between mean platelet volume and bronchopulmonary dysplasia and intraventricular hemorrhage in very low birth weight neonates. J Am Sci. 2012;8(5).

7. Chu SG, Becker RC, Berger PB, Bhatt DL, Eikelboom JW, Konkle B, et al Mean platelet volume as a predictor of cardiovascular risk: a systematic review and meta-analysis. J Thromb Haemost. 2010;8(1):148-56. doi: 10.1111/j.1538-7836.2009.03584.x. [PubMed: 19691485].

8. Canpolat FE, Yurdakok M, Armangil D, Yigit S. Mean platelet volume in neonatal respiratory distress syndrome. Pediatr Int. 2009;51(2):314-6. doi:10.1111/j.1442-200X.2009.02820.x. [PubMed: 19379270].

9. Dorling JS, Field DJ, Manktelow B. Neonatal disease severity scoring systems. Arch Dis Child Fetal Neonatal Ed. 2005;90(1):F11-6. doi: 10.1136/adc.2003.048488. [PubMed:15613564].

10. Parry G, Tucker J, Tarnow-Mordi W, U. K. Neonatal Staffing Study Collaborative Group . CRIB II: an update of the clinical risk index for babies score. Lancet. 2003;361(9371):1789-91. doi: 10.1016/S01406736(03)13397-1. [PubMed: 12781540].

11. Porter KB, O'Brien WF, Benoit R. Comparison of cord purine metabolites to maternal and neonatal variables of hypoxia. Obstet Gynecol. 1992;79(3):394-7. [PubMed: 1738522].

12. Pietz J, Guttenberg N, Gluck L. Hypoxanthine: a marker for asphyxia Obstet Gynecol. 1988;72(5):762-6. [PubMed: 3140152].

13. Batra S, Kumar R, Kapoor AK, Ray G. Alterations in antioxidant status during neonatal sepsis. Ann Trop Paediatr. 2000;20(1):27-33. [PubMed: 10824210].

14. Hooman N, Mehrazma M, Nakhaii S, Otukesh H, Moradi-Lakeh M Dianati-Maleki N, et al. The value of serum uric Acid as a mortality prediction in critically ill children. Iran J Pediatr. 2010;20(3):323-9. [PubMed: 23056724].

15. Chen HJ, Yau KI, Tsai KS. Urinary uric acid/creatinine ratio as an additional marker of perinatal asphyxia. J Formos Med Assoc. 2000;99(10):771-4. [PubMed: 11061072].

16. Bahubali DG, Bhat Vishnu B, Ramachandra R, Adhisivam B, Rojo J, Prasad P, et al. Biochemical marker as predictor of outcome in perinatal asphyxia. Cur Ped Res. 2013;17(2). 